\title{
SYSTEMATIC DECISION SUPPORT IN STRATEGY IMPLEMENTATION - A PROCESS FRAMEWORK AND APPLICATION OF $\alpha$-CUT FUZZY ANP
}

\begin{abstract}
In order to establish competitive advantages and facilitate long-term success it is of utmost importance for companies to embark on the right strategy. Any promising strategy can only succeed if it is implemented appropriately. During strategy implementation corporate management is facing several obstacles. There is a lack of guidelines and frameworks supporting strategy implementation to overcome these obstacles. Therefore, the objective of this paper is to develop a process framework for systematic decision support in strategy implementation based on the $\alpha$-cut fuzzy Analytic Network Process (ANP) approach. By conducting a case study, we demonstrate the suitability and practicability of the process framework to support management during selecting a supplier in line with the company's strategic goals.
\end{abstract}

Keywords: Analytic Network Process (ANP), $\alpha$-cut fuzzy approach, decision support system, process framework, strategy implementation.

\section{Introduction}

For companies it is crucial to embark on the right strategy to ensure long-term success. However, the best strategy does not generate value if it is implemented improperly. Therefore, it is a major challenge for corporate management to select the best action alternative in order to make the strategy work. For instance, in the field of supply management a major challenge is to select the supplier which fulfils strategic goals the best. Research shows that a majority of corporate management's decisions made with regard to action alternatives fail. To assist corporate management during strategy implementation we propose a process framework for decision support based on the $\alpha$-cut fuzzy Analytic Network Process (ANP) approach. The framework enables corporate management to compare several action alternatives systematically based on mutltiple evaluation criteria.

\section{Literature Review}

Despite the importance of implementing a strategy successfully, research neglected the topic in comparison to its relevance (Noble, 1999). Hrebiniak (2006) draws attention to the fact that there is a lack of guidelines and frameworks to support corporate management in strategy implementation. During strategy implementation, corporate management has to cope with several internal and external obstacles. This paper focuses mainly on the following three internal obstacles:

1) Alexander (1985) emphasizes that the existence of several conflicting action alternatives can lead to complications.

2) Dyson (2000) calls attention to the fact that focusing solely on financial measures is not suitable since financial measures are of lagging nature and therefore are not able to predict prospective performance.

3) Hrebiniak (2006) identifies a lack of detailed knowledge of corporate management as a core obstacle for strategy implementation. Further, he points out that relevant data and information is available in downstream divisions. 


\section{Objectives}

As literature provides only limited process-oriented and instrument-supported guidelines for strategy implementation, our objective is to develop a process framework for decision support that enables corporate management to master the three aforementioned obstacles. To do so, our proposed framework must be able (1) to compare the conflicting action alternatives in a systematic way in order to identify the alternative that is best suitable to achieve the strategic goals. (2) The framework should provide a rational and prospective evaluation of available action alternatives both on quantitative and qualitative factors. (3) The proposed decision-making approach must allow considering the opinion of a variety of experts in order to incorporate the downstream divisions' knowledge. Furthermore, our objective is to develop a process framework that reflects reality. In reality, the decisionmaker faces uncertainty which therefore has to be integrated into the approach.

\section{Research Design/Methodology}

To address the aforementioned requirements, we propose a process framework built upon the $\alpha$-cut fuzzy ANP method. By applying ANP appropriately and considering relevant division experts, we can cope with the three outlined obstacles. Additionaly, the $\alpha$-cut fuzzy approach enables to master the uncertainty.

Figure 1 presents our developed process framework. The framework comprises six phases (one row per phase). Each phase consists of different tasks. It also displays the involved parties per task (one column per party): corporate management, division experts, and the ANP-specialist. Figure 1 also illustrates how goals, evaluation criteria, action alternatives, and reciprocal influences are obtained. The applied tools and relevant data sources are provided in parentheses below the name of each phase. Examples drawn from the case study presented in section five are used for illustrative purposes on the right-hand side in figure 1. In specific phases, the overall judgement was calculated using the geometric mean. In case the consistency ratio surpasses a threshold of 0,2 , the pairwise comparisons have to be revised by division experts. Exceptions are only made when the expert upon request is highly confindent about his judgement (please refer to figure 4).

To address the uncertainty with respect to the evaluation of the pairwise comparisons we incorporated the $\alpha$-cut fuzzy approach in our model. Therefore, each division expert has to provide its confidence of judgement regarding each group of pairwise comparison in a scale between 0,0 and 1,0 with 10 increments in phase four. The experts also provide three values for each aforementioned evaluation. 
Ludwig Sedlmeier, Teresa Christmann-Schwaab, Constantin Schnupp, Klaus Möller

Chair of Controlling / Performance Management, University of St. Gallen

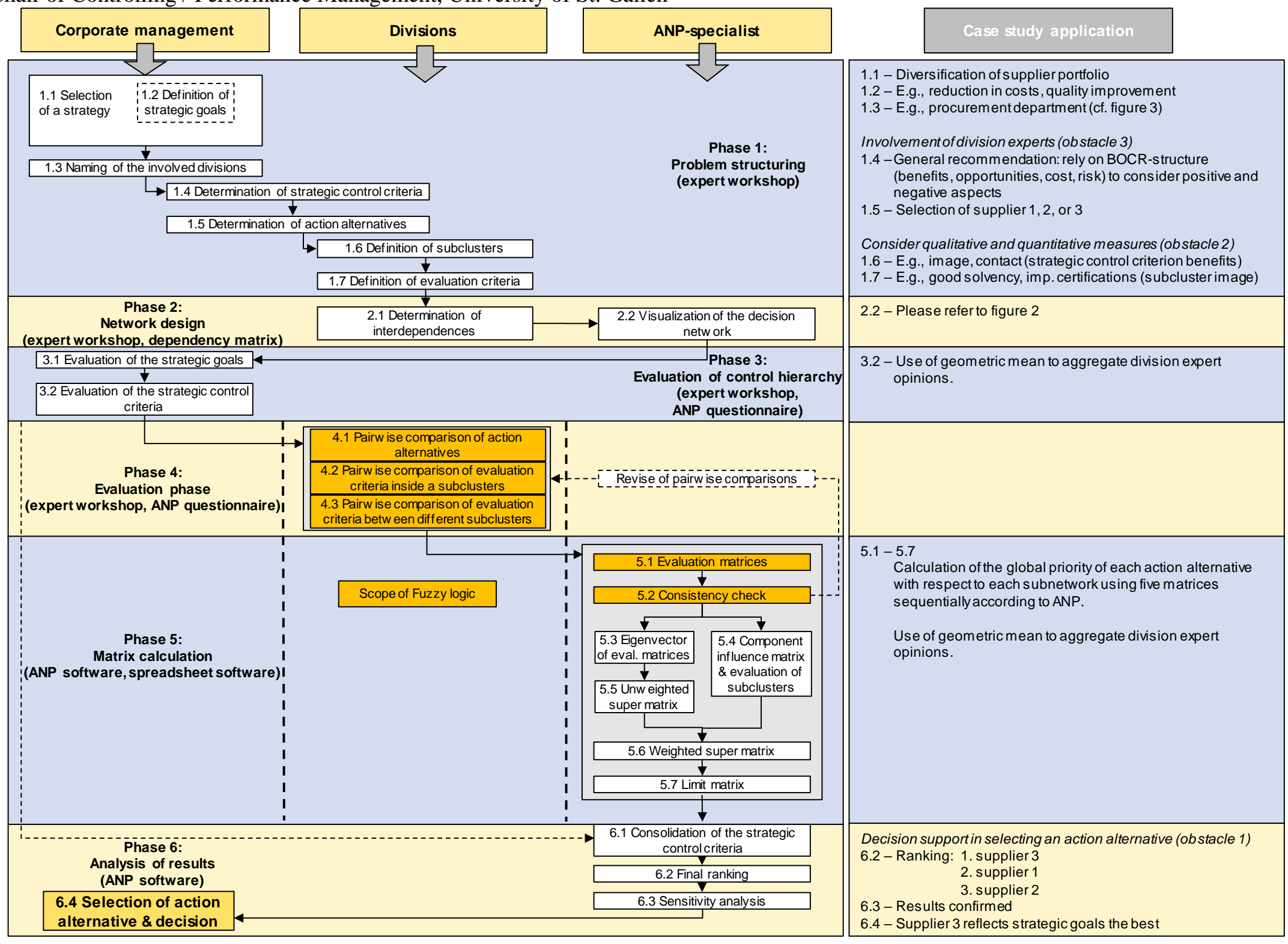

Figure 1: Process framework and its case study application

International Symposium on the Analytic Hierarchy Process 


\section{Data/Model Analysis}

The process framework was applied in a company in the printing industry. The corporate management had to master the challenge to revise the supplier portfolio, since through diversification the portfolio should be better aligned for future market shifts. Hereafter, we provide parts of the case study results such as the decision network, consistency ratios of the cluster "benefits" for each division, as well as the aggregated priorities of each division. Based on the empirical results, corporate management selected supplier 3 (please refer to figures 1 and 3).

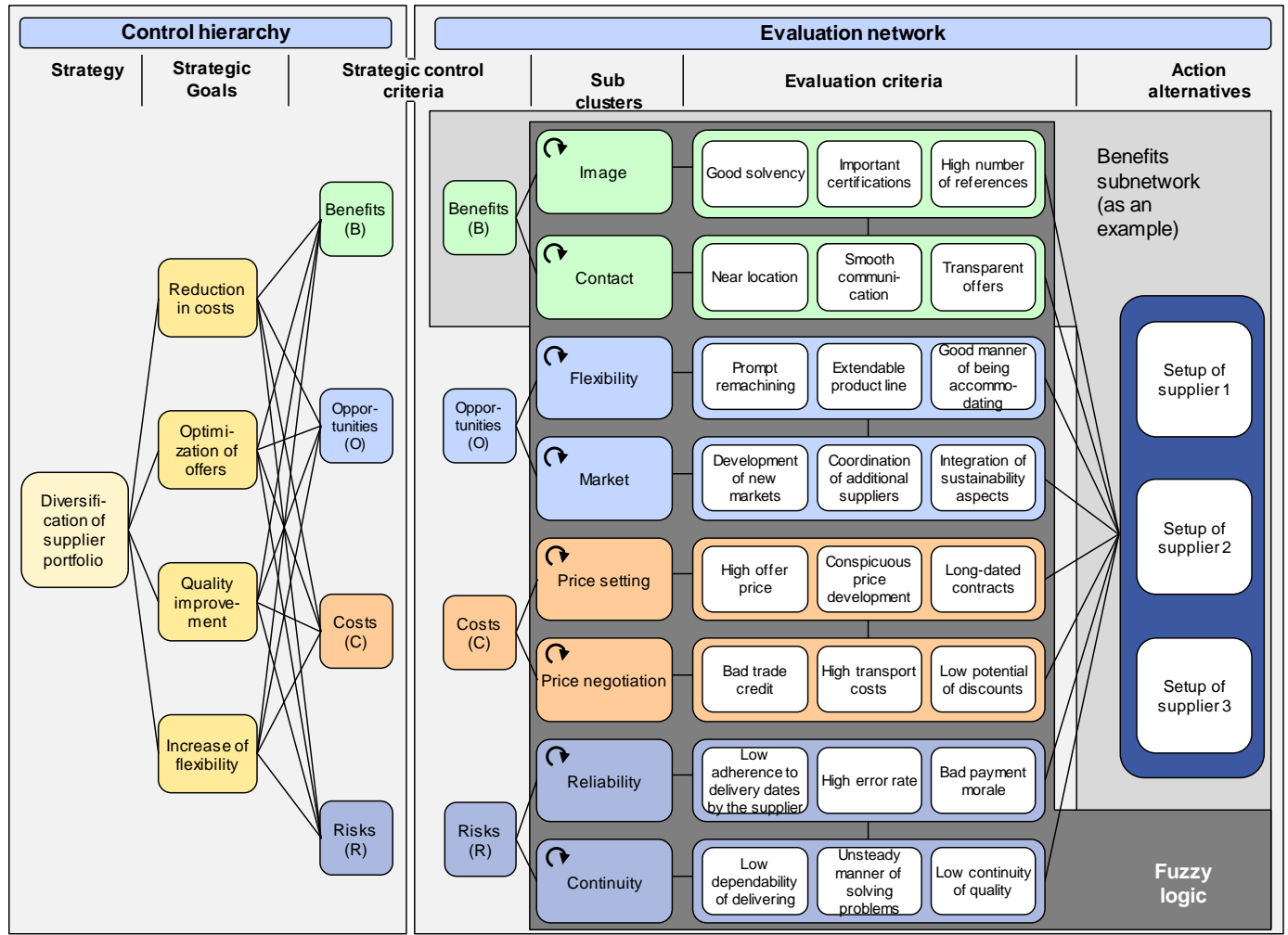

Figure 2: Decision network

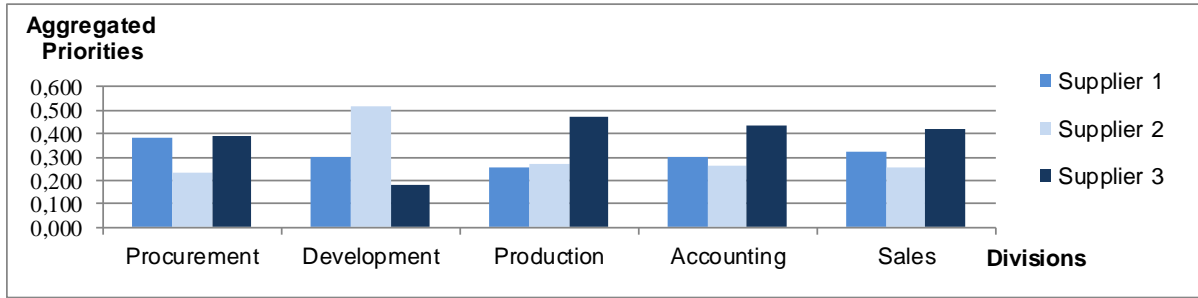

Figure 3: Aggregated priorities of each division

\begin{tabular}{|l|c|c|c|c|c|c|}
\hline Division & Solvency & Certifications & References & Location & Communication & $\begin{array}{c}\text { Transparency of } \\
\text { offers }\end{array}$ \\
\hline Sales & $9,0 \%$ & $28,4 \%$ & $13,0 \%$ & $13,0 \%$ & $17,0 \%$ & $8,2 \%$ \\
\hline Development & $3,7 \%$ & $13,0 \%$ & $0,5 \%$ & $5,2 \%$ & $9,0 \%$ & $13,0 \%$ \\
\hline Production & $10,0 \%$ & $17,0 \%$ & $9,0 \%$ & $10,4 \%$ & $7,1 \%$ & $7,3 \%$ \\
\hline Accounting & $1,8 \%$ & $7,1 \%$ & $13,0 \%$ & $3,1 \%$ & $5,2 \%$ & $7,7 \%$ \\
\hline Procurement & $1,8 \%$ & $0,0 \%$ & $13,0 \%$ & $8,2 \%$ & $15,7 \%$ & $5,2 \%$ \\
\hline \multicolumn{7}{|c|}{ C. $\boldsymbol{R} . \mathbf{> 0 , 2}$}
\end{tabular}

Figure 4: Consistency ratios (C.R.) of the cluster "benefits" for each division 


\section{Limitations}

To date, the process framework was applied within two companies (one of them is the case study presented above). Even if the usefulness was approved, the generalization of the framework is still limited. Besides, the following practical limitations exist. First, current available ANP-software is not capable of integrating the $\alpha$-cut fuzzy approach. By removing the fuzzy logic, the process would be more user-friendly because no additional fuzzy calculations are necessary. Second, the number of pairwise comparisons rises with an increase of the number of alternatives. Therefore, the approach is labor-intensive. Finally, the success of the approach depends highly on the precise definition of the decision problem, the selection of relevant evaluation criteria and the achievement of a common understanding across the different divisions involved.

\section{Conclusions}

The developed process framework for decision support in strategy implementation connects the research fields strategy implementation and operations research. Additionally, it addresses the gap between strategic and operational levels in a company. By relying on the process framework, the involved parties are forced to systematically structure the decision problem and to communicate with each other in a structured manner. The application of the process framework in a case study did not only provide proof of concept, but also supported corporate management with a valid and comprehensible basis for decision-making including aggregated expert opinions across the company. Further development of the process framework could be about modifying the weighting of each division expert or considering the opinion of external stakeholders such as customers.

\section{Key References}

Alexander, L. D. (1985). Successfully Implementing Strategic Decisions. Long Range Planning, 18(3), 91-97.

Dyson, R. G. (2000). Strategy, Performance and Operational Research. Journal of the Operational Research Society, 51(1), 5-11.

Hrebiniak, L.G. (2006). Obstacles to Effective Strategy Implementation. Organizational Dynamics, 35(1), 12-31.

Noble, C.H. (1999). The Eclectic Roots of Strategy Implementation Research. Journal of Business Research, 45(2), 119-134. 